\title{
Power, Identity, and the Construction of Knowledge in Education
}

\author{
Lana J. Vindevoghel \\ University of Regina
}

\begin{abstract}
This paper explores the social construction of knowledge, identity formation, and the ways in which the education system supports dominant societal ideology. I examine how dominant historical and societal ideologies are deeply cultivated and facilitated through education systems, including forcefully through the residential school system and, in many cases, subtly through post-secondary education. Further, I identify the method in which personal biases, predisposed by dominant social influence, are subconsciously reflected in the classroom through microaggressive behaviour. Weber's (2010) framework of themes provides a comprehensive perspective from which to understand the nature in which identity is influenced by dominant societal ideology. Finally, I analyze the social construction of knowledge, development of identity, and support of dominant ideology through Gramsci's concept of hegemony and Foucault's theory of discourse. The discussion then shifts to describe how conscientization and critical reflection can provide a step forward towards diminishing dominant societal ideology within the educational environment and create a path to embracing Freire's concept of liberating education.
\end{abstract}

Keywords: knowledge; identity; ideology; education

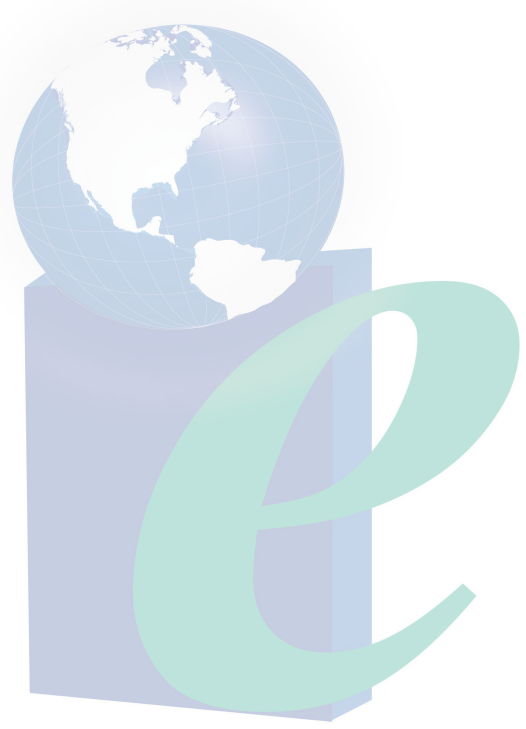




\section{Power, Identity, and the Construction of Knowledge in Education}

This paper explores the social construction of knowledge, the formation of identity, and the support of dominant ideology through the education system. I will examine how dominant social and historical ideology has been reflected in the education system forcefully through the residential school system, and how it can occur subtly within post-secondary education. The impact of dominant ideology and the formation of individual identity will be discussed including how personal biases, developed through social influence, are often subconsciously reflected in the classroom through micro-aggressive behaviour. Weber's (2010) five themes provides a comprehensive framework for understanding how dominant societal ideology influences identity and is further enculturated into the educational system. Finally, I will analyze identity, the social construction of knowledge and support of dominant ideology through Gramsci's concept of hegemony and Foucault's theoretical insight into discourse, knowledge, and power. At this point, the discussion will shift to illustrate how conscientization and critical reflection can provide an avenue to diminishing the support of dominant societal ideology within the education environment. I conclude with an explanation of Freire's (2013) concept of liberating education, and how using this concept can facilitate the deconstruction of dominant ideology.

Throughout this paper, I use the term ideology in a very broad and encompassing manner; I perceive it as encompassing societal and cultural common perceptions, beliefs, values, and theories that create ways of thinking, norms, realities, constructed truths, and behaviours. To understand the social construction of knowledge, I refer to the concept of social epistemology. According to Popkewitz and Brennan (1998),

epistemology provides a context in which to consider the rules and standards that organize perceptions, ways of responding to the world, and the conceptions of "self." Concurrently, social epistemology locates the objects constituted as the knowledge of schooling as historical practices through which power relations can be understood.(p. 9)

Within this context, knowledge is not viewed as separate; instead, it is a reflection of the social and historical context in which it was constructed. Social epistemology "consider[s] the word learning not as standing alone, but as embodying a range of historically constructed values, priorities and dispositions toward how one should see and act toward the world" (Popkewitz \& Brennan, 1998, p. 9). When exploring the transmission of knowledge and information within the education system, beliefs and values are incorporated into teaching and learning in a manner that often represents dominant societal perspectives. Learning, therefore, is not wholly dependent on the teacher or discipline; instead, it incorporates the use of terms, language, and dialogue that reflect historical beliefs and social culture. Within this framework, individuals construct knowledge in a manner that most often aligns with dominant societal ideology.

\section{Dominant Social and Historical Ideology Reflected in the Education System}

The transmission of knowledge through the education system has been built on the foundation of historical and societal ideology; however, reflecting on the education system brings to light questions such as, whose culture is predominant within the curriculum? What is the principal perspective reflected in the course content? Most importantly, whose history, values, and beliefs are absent from or marginalized by the existing system? These questions serve as an introduction to the discussion of how dominant social and historical ideology was forcefully transmitted through the residential school system and often subtly occurs in post-secondary education. 


\section{The Impact of Dominant Ideology: Forceful and Subtle}

Dominant ideology has forcefully been exhibited within education as demonstrated in the residential school system. "In 1971 Canada became the first country in the world to adopt multiculturalism as an official policy to underline the value of pluralism, including the rights of Aboriginal peoples” (Government of Canada, 2015, para. 1). The espousal of this policy is certainly holistic and encompassing; however, this course of action was established nearly half a century ago. In this time, how has the education system embraced and implemented this policy? It is evident that the residential school system was established, not as an endeavour to provide quality education, but was purposely created to assimilate Indigenous members of society to dominant Western ideology and "primarily break their link to their culture and identity" (Truth and Reconciliation Commission of Canada, 2015, p. 3). The consequences of this coercion of power have in many ways resulted in entire communities being stripped of identity, including language, beliefs, and values. The following is a brief excerpt from "Honouring the Truth, Reconciling for the Future," the summary of the final report written by the Truth and Reconciliation Commission of Canada (2015), which reflects the significant loss of identity, the sense of powerlessness, and the level of forced assimilation that took place in the residential school system as described by Doris Young, a member of the Elkhorn residential school in Manitoba. She states that upon her arrival at the school,

They gave us numbers, we had no names, we were numbers, and they cut our hair. They took away our clothes and gave us clothes...we all looked alike... [t]hey took away our moccasins, and gave us shoes. I was just a baby. I didn't actually wear shoes, we wore moccasins. And so our identity was immediately taken away when we entered those schools. (Truth and Reconciliation Commission of Canada, p. 145)

Indigenous culture and identity were eliminated through residential schools and replaced with Western ideology that was forcefully taught and engrained as truths. As a result, the greatest challenge, currently faced by educators may be the inclusion of a cultural history that dominant power structures have attempted to wipe from existence. The recent release of the Truth and Reconciliation Commission of Canada (2015) final report has provided an opportunity for educators to become aware of the importance of reflecting on existing educational structures in an effort to identify dominant societal and cultural ideology and realize the absence of Indigenous history.

Subtle or even incidental occasions of dominant ideology can also arise in education, often through the post-secondary system. Jakubowski and Visano (2002) indicate that learners are taught to view the world within dominant frameworks such as race, and it is within this context that "schooling' is intimately tied to the concept and reality of hegemony” (p. 30). Lichtenberg (1998) provides the realization that in many cases, prevailing beliefs, such as racial perspectives or tension, are often unnoticed, and that individuals "don't see themselves as harbouring animosity... they believe they hold to an ideal of equality, and of equal opportunity" (p. 43). Lichtenberg further identifies that cultural, racist perceptions or other forms of oppression exist not only as personal beliefs but also materially, often translated into complex actions or thoughts such as stereotyping, accommodating, or justifying personal or other people's racist behaviour. Dominant cultural or societal ideology often fosters the development of deeply engrained biases or beliefs such as racism; these perceptions can often become overlooked and therefore subconsciously subjected onto others, such as students. Jakubowski and Visano (2002) 
present the perspective that traditional pedagogical instruction creates a sense of dependency between students and teachers, providing an opportunity for hegemonic ideologies and beliefs to be transferred to the students; therefore, "the process of 'schooling' leaves little room for 'reframing,' critical thought, empowerment or action” (p. 33). Within this context, the educational system supports the subtle reproduction of dominant cultural and societal thinking and practices, such as racism, leaving little chance for the construction of knowledge or formation of individual identity outside of this framework.

Formation of individual identity. Establishing an awareness of the relationship between the development of identity and dominant societal and cultural ideology contributes to understanding how subtle or unintentional acts of bias or prejudice can occur within the education system.

Micro-aggression. Brookfield (2015), in his book The Skillful Teacher: On Technique, Trust, and Responsiveness in the Classroom, refers to his cultural identity and background as a White, Euro-American male professor growing up in Britain. In his writing, he discusses the concept of micro-aggressive behaviour and recounts an experience in which he expressed racial micro-aggression in the classroom. Micro-aggressions are considered to be "small acts of exclusion and marginalization committed by a dominant group toward a minority" (Brookfield, 2015, p. 119). This form of racial aggression is not overt and is often performed without a conscious awareness. In an experience described by Brookfield (2015), he had decided to summarize a class lecture by asking the students the main themes they had learned from the discussion. When he was satisfied with the class summary, one of the students mentioned that he had missed asking the opinion of a female student of color. Reflecting on this situation, Brookfield initially attributed his behaviour as forgetfulness, yet after further thought, he realized that this was an example of micro-aggressive behaviour. Incidentally, when he apologized to the student, she mentioned that a similar occurrence had happened in each of the classes she had taken at the university.

In the above example, Brookfield described his historical background and the engrained societal stereotypes he had been taught as truths during his upbringing. He acknowledged that although he attempted to remain unbiased, the historical context in which he developed his identity remained part of his subconscious and actions. Vincent (2003) explains that individuals are assigned identities within society that include presumptions or bias, and simultaneously create personal identities. Although individuals are free to develop their self-image or identity, it is not, however, within the context of their choosing. Vincent (2003) draws upon Hall's (1993) comment that

cultural identities come from somewhere, have histories. But... far from being eternally fixed in some essentialist past, they are subject to the continual play of history, culture and power... identities are the names we give to the different ways we are positioned by, and position ourselves within, the narratives of the past. (p. 5)

Not only do students develop socially and historically constructed identities within restrained possibilities, but teachers, too, are continually re-aligning and transforming individual identities, influenced by corporate and social expectations (Vincent, 2003). Brookfield's (2015) story illustrates a valuable lesson: Educators must be cognizant of the difficulty in recognizing how identity is developed within and how it is influenced by historical context including the 
presumptions or biases that may remain at a subconscious level, and thus can be inadvertently expressed within the educational environment.

Weber's (2010) comprehensive framework. To more fully understand the formation of identity developed within dominant societal ideology and the relationship to the educational system, it is useful to review the five themes proposed by Weber (2010). This framework offers a comprehensive lens for examining how individual identity is developed within, and is affected by, societal ideology, including (a) historical and geographical context, (b) the impact of societal constructs, (c) the operation of power relationships at (d) macro social-structural and micro social-psychological levels, and (e) the simultaneous expression of power throughout macro and micro levels (Weber, 2010). An examination of these themes brings to light societal factors that influence the development of identity and the intersectionality that occurs between each. Weber (2010) indicates that to "focus on only a single dimension, although useful for some purposes, [is] ultimately partial” (p. 92). The first three themes recognize the significance that historical, geographical, and societal contexts have on the development of identity, which are further reflected in the construction of societal and cultural knowledge, beliefs, and norms. The fourth and fifth themes highlight the potential for micro-aggressive or other personal bias behaviours to become forcefully or subtly integrated into the learning environment during the development or delivery of curriculum. Weber's proposed themes provide an inclusive view of how dimensions such as power relations, dominance, and historical and societal contexts intersect and influence the formation of individual identity and are further enculturated into the education system. This framework is a useful guide for educators to understand the complexity of factors that affect the development of identity. It could also be used as a tool for self-reflection and aid in establishing an appreciation for individual differences.

\section{Gramsci’s Concept of Hegemony}

The concept of hegemony surfaces when analyzing the relationship between knowledge construction, identity formation, and the support of dominant societal ideology within educational systems. In many cases hegemony is perceived to be the domination of one class or social group over another; however, according to Gramsci (as cited in Femia, 1981), "hegemony is the predominance obtained by consent rather than force of one class or group over other classes" (p. 24). Gramsci's conceptualization of hegemony indicates that power is achieved when everyday thoughts and behaviours, based on historical and societal influence, are learned and constructed as truths. Hegemony is further described by Gramsci (as cited in Fontana, 1993)as grounded in economic roots in which societal structures exhibit power to "translate the interest and values of a specific social group into general, 'common' values and interests” (p. 141). Through the use of social structures such as the education system, citizens can be led to develop identity in which similar worldviews that represent what is considered to be the best interests of civil society are internalized. These socially constructed truths become deeply embedded and hegemonic behaviour is therefore achieved through the assimilation to prevailing beliefs and dominant ideology (Fontana, 1993). Individuals and social structures, such as the education system, cannot be seen as separate from hegemony, but in fact should be considered an active contributor, because the knowledge constructed and supported through teaching and learning as well as subsequent actions that take place continually maintain and reinforce dominant ideology. 


\section{Foucault's Insights Into Discourse, Knowledge, and Power}

Foucault (as cited in Luke, 1995) provides an analysis of discourse, knowledge, and power with the acknowledgment that each acts as a stimulant in the production of the other. He conceptualizes that the construction of words, statements, and phrases used in both spoken and written text create meaning that we live by, and he suggests that societal structures serve as the foundation in which language comes together to form understanding, ways of knowing, and systems of belief. Foucault's (as cited in Luke, 1995) theory of discourse and the construction of knowledge provides educators with a distinct perspective to view curriculum. Through his insights on the use of language it is understood that educational materials should be viewed as artifacts of the history within which they were developed. The development of curriculum and delivery of education, therefore, cannot be seen as separate from historical or societal context. Knowledge is constructed within prevailing cultural and social values, beliefs, and ideals; therefore, concepts such as power or dominance can become deeply embedded and interwoven into societal structures, including the delivery of education. Foucault (as cited in Luke, 1995) theorizes that "schools and other significant social institutions are constituted by discourse and discursive relations" (p. 9). This brings to light the pedagogical connection between the creation of knowledge, production of power, and support of dominant ideology.

\section{Teaching and Learning With Conscientization, Critical Reflection, and Liberating Education}

\section{Teaching and Learning With Conscientization}

At this point, the discussion will shift to illustrate how teaching and learning with conscientization, critical reflection, and liberating education can establish a path towards diminishing the support of dominant societal ideology within the educational environment. To begin, I would like to recall Freire's (as cited in Lloyd, 1972) theory of conscientization that defines the process in which individuals are seen "not as recipients, but as knowing subjects, achiev[ing] a deepening awareness both of the socio-cultural reality which shapes their lives and of their capacity to transform that reality” (p. 5). Fidyk (2008) discusses Freire's theory of conscientization within education as a transformation of consciousness that creates an opportunity for educators to become aware of their teaching in relation to society and the world, and to challenge internalized and socially constructed beliefs and power relations. Fidyk (2008) describes conscientization within education as a pedagogy that should see "students beyond local time and space... [and] consider the influence of culture, history, gender, race, [and] emotions” (p. 152). Further, conscientization within education would allow students and educators to develop a level of awareness in which "one is not borrowing from the past, re-shaping, reforming, and re-arranging. Rather [one is turning] away from backward and forward visions to a disciplined practice of living in the present” (Fidyk, 2008, p. 148). Within this context, teaching and learning would actively reflect upon the influence of socially and historically structured realities and truths and incorporate this cognizance in the development and delivery of curriculum. From this perspective, the construction of knowledge and further development of identity could begin to take place outside of dominant historical and societal ideology.

Fidyk (2008) proposes that conscientization creates a shift in perspective from one that is fundamentally socially influenced to one that becomes inherently aware of the connections between teaching, learning, and the potential for the betterment of society, both locally and 
globally. This framework of conscientization acknowledges a connection between the learning environment and humanity as well as one that that exists between all entities. Incorporating this level of awareness within teaching and learning practices would allow students to construct and share knowledge, and to develop identity in a way that demonstrates ethical awareness within a global and environmental context. With each classroom being comprised of students who have a myriad of backgrounds, cultures, and worldviews, the employment of conscientization would provide the opportunity for educators to facilitate an open learning environment in which the teacher can learn from the students and the students can learn from one another, while each individual remains aware of the inter-relatedness between each other within the classroom, the community, and the world (Fidyk). The application of conscientization within the classroom provides an avenue for educational systems to adopt thoughtful and deliberate teaching and learning outside of dominant societal ideology.

\section{Conscientization and Indigenous Education}

Teaching and learning with a conscious connection towards humanity, the environment, and all global entities also aligns with Indigenous learning. Many existing educational systems anchored in a Western worldview have been aspiring to indigenize education. This form of teaching and learning would provide a greater opportunity for educators to integrate conscientization and pedagogy. Mussell (2008) indicates that indigenization within education systems should be designed to support identity, disempower existing structures of dominance, and "bring together Indigenous and Western paradigms and practices" (p. 331). Indigenization would create an opportunity to facilitate education that reflects historical and societal culture in a manner that is holistic and inclusive, recognizing that "what is considered truth under one paradigm of knowledge may not be so in another” (Michell, 2005, p. 36). The significance of conscientization in teaching and learning is that it includes an awareness that knowledge conceived within the influence of societal or cultural structures is not a holistic representation of all beliefs or views.

Indigenous learning also engages a connection between the classroom and culture, embracing a level of cognizance that incorporates "participation with the natural world with all of ones' senses, emotions, body, mind and spirit, under the guidance of elders, cultural teachings and practices” (Michell, 2005, p. 36). Knowledge is facilitated through both classroom and cultural practices such as spiritual ceremonies and daily activities, and learning is enriched with consideration for the land and everyday world. Through this epistemology, knowledge construction becomes complete, combining a personal, spiritual, and collective awareness that provides ongoing respect and support for the community and natural world. In this type of education environment, conscientization can enhance teaching and learning in a manner that recognizes learning beyond the classroom into a community, global, and humanitarian context. Conscientization can, therefore, reduce the cycle of realities and truths that are founded on prevailing or assimilated beliefs, and help to diminish the support of dominant societal ideology.

\section{Critical Reflection}

In addition to conscientization, critical reflection can provide a step forward to decreasing the support of dominant societal ideology within education. According to Brookfield (1995), the genuine interest in providing a learning environment that is anticipated to be respectful and encompassing of all students can often be experienced in a manner that is marginalizing or 
oppressing to learners. The intention of teaching in a manner that is completely free of bias or assumptions and providing a learning environment that upholds the beliefs of all students is convoluted by the "cultural, psychological and political complexities of learning, and the ways in which power complicates all human relationships (including those between students and teachers) mean[ing] that teaching can never be innocent” (Brookfield, 1995, p. 1). Critical reflection can provide an avenue to assist educators with identifying personal bias or assumptions that can often go unnoticed in the development and delivery of teaching and learning activities.

Critical reflection should not, however, be reserved strictly for teaching methodologies, instead, it should be applied holistically to all aspects of education including curriculum, texts, dialogue, and content. Brookfield (1995), discusses the method in which becoming a critically reflective educator identifies "how the dynamics of power permeate all educational processes [and] helps us realize that forces present in the wider society always intrude into the classroom" (p.7). Through the use of critical reflection, socially constructed biases, assumptions and the influence of power structures within education can begin to be discovered. Critical reflection views education within the context of both time and space, with the potential of reproducing the imbalance between dominant or marginalized cultures (Brookfield). It is within this context that a critically reflective educator would examine assumptions and rationale and evaluate each of these from a broadened perspective to determine if power structures are being maintained or inequities are present (Brookfield). Critical reflection is an effective method for revealing hegemony within the education system and exploring how processes that may be perceived as neutral in fact serve to support power structures and dominant societal ideology.

\section{Deconstruction of Dominant Ideology Through Liberating Education}

Freire (2013) introduces the concept of liberating education as a method to empower students and aid in the deconstruction of dominant ideology. Education, although often not performed with the intent to oppress, teaches students within a prescribed framework of beliefs and ideologies, often providing little opportunity for the application of critical thinking. Freire (2013) states, "Education as the exercise of domination stimulates the credulity of students, with the ideological intent (often not perceived by the educators) of indoctrinating them to adapt to the world of oppression" (p. 78). Friere (2013) refers to this lack of critical teaching as the banking concept of education in which the students are perceived to be deficient in any existing skills or expertise that can be applied within the learning environment and the teacher is considered the only individual that can aid in the construction of knowledge and facilitation of learning (Freire, 2013). In this context, the students focus on storing the knowledge transmitted by the teacher, leaving insufficient opportunity to cultivate a critical consciousness or develop an individual identity and a perspective of the world beyond the reality presented(Freire, 2013). Even educators that seek liberating education are often enveloped by an educational system that supports the banking concept.

Freire (2013) suggests that to provide truly liberated education, the banking concept must be completely rejected and replaced instead by problem-posing education, which recognizes the significance of knowledge and comprehension that learners contribute to the facilitation of education. This level of consciousness is not only to be applied to the learner's perspective of worldview but also turned on one's self, to a state of mindfulness of intent (Freire, 2013). In this context, students are no longer considered passive learners; they, instead, are engaged with the 
teacher as an active contributor to the learning environment. The students' existing knowledge is integrated into the learning process through discussion and the exchange of ideas. The teacher becomes liberating, and "is no longer merely the-one-who-teaches, but one who is himself [or herself] taught in dialogue with the students, who in turn being taught also teach” (Freire, 2013, p. 80). The concept of liberating education provides greater opportunity for educators to identify socially constructed truths and worldviews and to employ engaged teaching and learning, a method in which the teacher can truly learn from the students and guide them in their relationship with the world. Through the process of liberating education, educators strive to recognize existing frameworks of dominant ideology and construct knowledge in a manner that shares ideas of all students within the classroom while incorporating a conscious connection beyond the classroom, extending to the community and global context.

\section{Conclusion}

In this paper, I have explored the social construction of knowledge, identity formation, and the manner in which the education system supports dominant societal ideology. Although the correlation between each is not explicit, it is clear that to work towards a liberating teaching and learning environment, "educators must challenge the constructions of truth operating in prevailing educational discourses that perpetuate dominant social structure and power relations" (Brown \& Land, 2005, p. 3). The route, however, to liberating education is tasked with a myriad of challenges including the influence of historical and societal constructs and persisting structures of banking education. Even educators that attempt to incorporate conscientization and critical reflection are often surrounded by existing educational practices that, in many cases, promote an "assembly-line approach to learning" (hooks, 1994, p. 13). Each of these issues adds to the complexity of providing an education system in which dominant ideology does not prevail.

In many ways, knowledge is created within dominant social, political and cultural forces, and is recurrently communicated and supported through a variety of influences including parents and family members, care providers, social structures, media, and of course the education system. It is within the educational system that informal and formal learning may be framed in and perpetually augmented by existing power, ideology, and dominance. Educators are faced with the daunting responsibility of remaining cognizant of historical and societal influences and creating a system that provides teaching and learning in a manner that is liberating and empowering. Although challenging, this should not be considered an impossible feat. Brookfield (1995) emphasizes the significant impact the education system can have: "We teach to change the world" (p. 1). Through the process of conscientization and critical reflection, the subtleties of dominant societal ideology can be revealed and a path to liberating education can be created. Education that includes ongoing critical reflection within the classroom and a conscious perspective of the connection to local and global society can, in fact, become an avenue to change the world. 


\section{References}

Brookfield, S. (1995). Becoming a critically reflective teacher. San Francisco, CA: Jossey-Bass.

Brookfield, S. (2015). The skillful teacher: On technique, trust, and responsiveness in the classroom ( $3^{\text {rd }}$ ed.). San Francisco, CA: Jossey-Bass.

Brown, M. C., \& Land, R. (Eds.). (2005). The politics of curricular change: Race, hegemony, and power in education (Vol. 131). New York, NY: Peter Lang.

Femia, J. (1981). Gramsci’s political thought. New York, NY: Oxford University Press.

Fidyk, A. (2008). Democracy and difference in education: Interconnectedness, identity, and social justice pedagogy. In D. Lund, \& P. Carr, P. (Eds.), Doing democracy: Striving for political literacy and social justice (pp. 139-157). New York, NY: Peter Lang.

Fontana, B. (1993). Hegemony and power. Minneapolis, MN: University of Minnesota Press.

Freire, P. (2013). Pedagogy of the oppressed. New York, NY: Bloomsbury.

Government of Canada. (2015). Annual report on the operation of the Canadian Multiculturalism Act - 2013-2014. Retrieved from http://www.cic.gc.ca/english/resources/publications/multi-report2014/3.asp

hooks, b. (1994). Teaching to transgress. New York, NY. Routledge.

Jakubowski, L. M., \& Visano, L. A. (2002). Teaching controversy. Halifax, NS: Fernwood Books.

Lichtenberg, J. (1998). Racism in the head, racism in the world. In N. Zack, L. Shrage, \& C. Sartwell (Eds.), Race, class, gender, and sexuality: The big questions (pp. 43-48). Malden, MA: Blackwell.

Lloyd, A. (1972). Freire, conscientization, and adult education. Adult Education, 23(1), 3-20. doi: 10.1177/074171367202300101

Luke, A. (1995). Text and discourse in education: An introduction to critical discourse analysis. Review of research in education, 21, 3-48. doi: 142.3.100.23

Michell, H. (2005). Nehithawak of Reindeer Lake, Canada: Worldview, epistemology and relationships with the natural world. The Australian Journal of Indigenous Education, 34, 33-43. Retrieved from http://search.informit.com.au.libproxy.uregina.ca:2048/fullText;dn=146251173019632;re $\underline{\mathrm{s}=I E L I N D}$

Mussell, W. (2008). Decolonizing education: A building block for reconciliation. In M. B. Castellano, , L. Archibald, , \& M. DeGagné, (Eds.), From truth to reconciliation: Transforming the legacy of residential schools (pp. 319-338). Ottawa, ON: Aboriginal Healing Foundation. Retrieved from http://speakingmytruth.ca/downloads/AHFvol1/AHF_TRC_vol1.pdf

Popkewitz, T. S., \& Brennan, M. (1998). Foucault's challenge: Discourse, knowledge, and power in education. New York, NY: Teachers College Press. 
Truth and Reconciliation Commission of Canada. (2015). Honouring the truth, reconciling for the future. Retrieved from

http://www.trc.ca/websites/trcinstitution/File/2015/Honouring_the_Truth_Reconciling_fo r_the_Future_July_23_2015.pdf

Vincent, C. (Ed.). (2003). Social justice, education and identity. New York, NY:

RoutledgeFalmer.

Weber, L. (2010). Understanding race, class, gender, and sexuality: A conceptual framework. New York, NY: Oxford University Press. 